\title{
Influência do sistema de colheita nas características da fibra do algodão ${ }^{1}$
}

\author{
Elizabeth Haruna Kazama ${ }^{2 *}$ Francielle Morelli Ferreira ${ }^{3}$, Antonio Renan Berchol da Silva, \\ Diego Augusto Fiorese 5
}

$10.1590 / 0034-737 X 201663050006$

\section{RESUMO}

Escolhas no manejo cultural, como a do cultivar e a do sistema de colheita, podem influenciar os índices dos parâmetros de qualidade da fibra do algodão. Objetivou-se, com este trabalho, analisar as características das fibras de dois cultivares de algodão submetidos a diferentes sistemas mecanizados de colheita (picker e stripper). O experimento foi conduzido na safra de 2012, com espaçamento de 0,45 m entre linhas, no município de Juscimeira, MT. Utilizou-se delineamento em blocos casualizados, em esquema de parcelas subdivididas, com dois fatores, sendo eles, A, nas parcelas (dois cultivares) e B, nas subparcelas (três sistemas de colheita - manual, picker e stripper), com cinco repetições. A qualidade da fibra foi determinada em amostras coletadas manualmente da planta e, após a colheita mecanizada, retiradas de dentro do cesto armazenador de cada colhedora. As análises das características das fibras foram realizadas em Laboratório de Classificação de Fibras, com o aparelho HVI (High Volume Instrument). As fibras do algodão colhido com o sistema manual, em seguida, sistema picker apresentam melhores características e melhor qualidade que as das fibras colhidas com stripper.

Palavras-chave: colhedora; picker; stripper; qualidade da fibra; Gossypium hirsutum.

\section{ABSTRACT}

\section{Influence of harvesting system in cotton fiber characteristics}

Choices in crop management such as cultivar and harvesting system can influence fiber quality parameters. This study aimed to evaluate fiber characteristics of two cultivars in narrow row cotton submitted to different mechanized harvesting systems (picker and stripper). The experiment was conducted in season 2012, with $0.45 \mathrm{~m}$, at Juscimeira MT. It was used randomized block design in split plot with two factors, factor A in the plots (two cultivars) and factor $\mathrm{B}$ in the subplots (three harvesting systems - manual, picker and stripper), with five replications. The quality of the fiber was determined in manually collected samples of plants and after harvest, withdrawn inside the basket of each harvester. The analysis of the characteristics of fiber, were analyzed in Laboratory of Classification of Fiber in apparatus by HVI (High Volume Instrument). Fibers picked with manual, followed by picker system have characteristics and better quality compared to fibers harvested with stripper.

Key words: harvester; picker; stripper; fiber quality; Gossypium hirsutum.

\footnotetext{
Submetido em 28/04/2015 e aprovado em 30/03/2016.

${ }^{1}$ Este trabalho é parte da dissertação de mestrado da segunda autora.

${ }^{2}$ Universidade Estadual Paulista Júlio de Mesquita Filho, Departamento de Engenharia Rural, Jaboticabal, São Paulo, Brasil. bethkazama@hotmail.com

${ }^{3}$ Universidade do Estado de Mato Grosso, Departamento de Agronomia, Alta Floresta, Mato Grosso, Brasil. francielle @unemat.br

${ }^{4}$ Universidade Federal de Mato Grosso, Departamento de Solos e Engenharia Rural, Cuiabá, Mato Grosso, Brasil. renanberchol@hotmail.com

${ }^{5}$ Universidade Federal de Mato Grosso - UFMT, Instituto de Ciências Agrárias e Ambientais - ICAA. Sinop - MT - Brasil. dafiorese@yahoo.com.br

*Autora para correspondência: bethkazama@hotmail.com
} 


\section{INTRODUÇÃO}

O algodão é uma importante fibra natural, considerada globalmente a principal das culturas de fibras (Pujer et al., 2014). Com a elevação dos preços dos fertilizantes, combustíveis e mão de obra, uma das alternativas encontradas por pesquisadores e cotonicultores para redução dos custos de produção foi o estreitamento do espaçamento entre fileiras no algodoeiro. Essa técnica, que surgiu nos anos 70 nos Estados Unidos da América, visa à diminuição do ciclo da cultura e possibilita a redução das aplicações fitossanitárias, com isso, há menor interferência de plantas daninhas, maior precocidade e, consequentemente, menores custos de produção, podendo apresentar, portanto, vantagens sobre o sistema de cultivo convencional. Segundo Rosolem et al. (2012), no sistema adensado o número final de frutos por planta não é superior a cinco ou seis, diminuindo o período de florescimento.

O Estado de Mato Grosso atualmente é o maior produtor de algodão (Gossypium hirsutum L.) do Brasil. Na safra de 2013-2014, foram cultivados 645.916 hectares e colhidas 995.013 toneladas de algodão em pluma (IMEA, 2014), representando 57,38\% da produção nacional (CONAB, 2014). O país aparece em quinto lugar no ranking mundial, com produção total, na última safra, de 1.734 .000 toneladas de algodão em pluma.

O cultivar FMT 701, pertencente à Fundação Mato Grosso, é recomendado para cultivo em todo o Brasil, apresenta ciclo tardio, porte de planta alto e formato de planta cilíndrico, folhas pouco pilosas, com maçãs de forma ovalada e tamanho médio; rendimento de fibra de 39 a $42 \%$ na algodoeira e aderência de fibra mediana (Fundação Mato Grosso, 2012).

O cultivar IMACD 408, pertencente ao Instituto Matogrossense do Algodão, apresenta folhas médias, pouco pilosas e bem recortadas. De ciclo intermediário, é um material de arquitetura piramidal, adaptado tanto à colheita mecânica como à manual, com média retenção de pluma. Esta variedade é moderadamente exigente em fertilidade, mas responsiva, com alta retenção de frutos nas primeiras posições e rendimento de fibra em torno de $44 \%$ (PupimJúnior et al., 2005).

Uma etapa de alto custo e de extrema importância no processo produtivo do algodão é a colheita, uma vez que, se mal conduzida, acarretará prejuízos de qualidade e de quantidade ao produto final.

Para a colheita do algodão, existem dois tipos de máquinas: a colhedora de fusos (picker), é bastante seletiva, os fusos puxam a fibra do capulho aberto e quando a colhedora está bem ajustada, a quantidade de matéria estranha levada para o cesto (sujeira grossa) é razoável, a contaminação vegetal é média, com casquilhas, caules e folha, já a colhedora stripper, dotada de sistema de rolda- nas, retira os capulhos inteiros, as casquilhas e os invólucros (Embrapa, 2003).

As colhedoras do tipo picker têm como principal elemento os fusos em rotação, que extraem de forma seletiva o algodão em caroço dos capulhos, sem puxar as casquilhas (Belot \& Vilela 2006). As colhedoras do tipo stripper são compostas por um conjunto de dedos, formando um pente (de largura que pode variar entre 3,0 e 7,2 m) (Silva et al., 2010). No sistema de colheita stripper, o molinete bate nas plantas e a máquina recolhe os capulhos com brácteas e fragmentos lenhosos (Martin, 2006).

A qualidade intrínseca das fibras é dependente do fator genético, próprio de cada cultivar, e de fatores do ambiente, como temperatura, umidade relativa do ar e radiação solar (Sestren \& Lima, 2015). Baxevanos et al. (2013) observaram que as variáveis percentagem de fibra e alongamento são fortemente controlados pelo genótipo, enquanto resistência, comprimento e uniformidade são moderadamente controlados pelo genótipo e o índice de fibras curtas e a cor são fracamente controladas pelo genótipo. Todas essas mesmas variáveis, porém, sofreram forte influência do fator ambiental (fenótipo), em especial produtividade, resistência, índice de fibras curtas, amarelecimento e reflectância, em ensaio com seis cultivares comerciais, realizado, por cinco anos, na Grécia. Características como micronaire (indicativo da relação finura/maturidade da fibra), amarelecimento são tanto geneticamente controladas quanto impactadas pelas condições ambientais (Krieg \& Hequet, 2005; Saha et al., 2008).

Analisando-se as características da fibra em função de diferentes sistemas de colheita, a manual, por ser mais seletiva, provoca pouca contaminação. Nessa modalidade, $o$ rendimento de fibra é alto (40 a 45\%); a sequência de beneficiamento é mínima, com menos tratamentos mecânicos. A fibra é limpa, com baixas taxas de fibras curtas e neps (pequenos emaranhados de fibras menos resistentes, como as imaturas ou mortas (Iype \& Wan, 1998), além dos tipos produzidos, que são de melhor qualidade.

A busca da indústria têxtil em geral é por plumas com maiores percentuais de reflectância, menores índices de amarelecimento e menor grau de impurezas. Portanto, o manejo do algodoeiro está diretamente relacionado com a qualidade da fibra, uma vez que o sistema de produção e o tipo de colheita podem afetar o produto final.

Por esses motivos, objetivou-se, com este trabalho, avaliar as características das fibras de dois cultivares de algodão, em cultivo adensado, submetidos a diferentes sistemas mecanizados de colheita (manual, picker $e$ stripper).

\section{MATERIAL E MÉTODOS}

O experimento foi conduzido no ano agrícola de 2012, em Juscimeira, Mato Grosso. A área experimental apresen- 
ta coordenadas geográficas aproximadas de $16^{\circ} 22^{\prime} 16.92 "$ $\mathrm{S}, 55^{\circ}$ 6' 55.99" O e altitude média de $505 \mathrm{~m}$. De acordo com a classificação de Köppen, o clima da região é o tropical sazonal, com invernos secos e verões chuvosos. O solo da área experimental foi classificado como LATOSSOLO Vermelho de textura média (Embrapa, 2006).

O algodão foi produzido em sistema de cultivo adensado, semeado em 04 de janeiro de 2012, sob sistema de semeadura direta (palhada de milheto e capim-sudão), com espaçamento de $0,45 \mathrm{~m}$ entre fileiras de plantas.

Os dados de precipitação pluviométrica foram coletados por pluviômetro, presente na área experimental em todo o ciclo da cultura. O total acumulado de janeiro a julho foi de 1129,5 mm. Na Figura 1, é apresentada a distribuição de chuvas nesse período.

Utilizou-se o delineamento de parcelas subdivididas em blocos casualizados (DBC), sendo considerados dois níveis para o fator A (dois cultivares, FMT 701 e IMACD 408) e três níveis para o fator B, ou seja, três sistemas de colheita (manual, picker e stripper), com cinco repetições.

Na ocasião da colheita, em julho de 2012, foram utilizadas as seguintes máquinas: Colhedora de algodão do tipo picker, marca John Deere, modelo 9970, com potência de $186 \mathrm{~kW}$ ( $253 \mathrm{cv})$, ano 2001, com 1.902 horas trabalhadas, com plataforma de 4,5 $\mathrm{m}$ de largura e dez linhas de colheita com kit Cotton 45, da Deltamaq Indústria e Comércio Ltda; Colhedora de algodão marca Case, modelo 2555, com potência de 193 kW (263 cv), ano 1998, com 3.718 horas trabalhadas, adaptada com plataforma de "pente", fabricada na própria fazenda (réplica do modelo da marca BUSA), com $6 \mathrm{~m}$ de largura e sistema de colheita stripper.

As amostras de algodão em caroço, oriundas da colheita manual e da colheita mecanizada (retiradas do cesto armazenador das colhedoras) foram beneficiadas em máquinas de rolo, pela Fundação MT, em Rondonópolis, MT. As características da fibra (percentagem de fibra, micronaire, comprimento, uniformidade de comprimento, maturidade, resistência, índice de fibras curtas, amarelecimento, cor, reflectância, impurezas, área, etc) foram analisadas em Laboratório de Classificação de Fibras da BM\&F, em Rondonópolis, MT, com o sistema HVI (High Volume Instrument).

Os resultados de produtividade do algodão em caroço por colheita manual, realizada em cada parcela antes da passagem das colhedoras, alcançaram $3.911 \mathrm{~kg} \mathrm{ha}^{-1}$, para o cultivar FMT 701, e $4.108 \mathrm{~kg} \mathrm{ha}^{-1}$, para o cultivar IMACD 408. O teor médio de água no algodão em caroço na colheita foi de $9,5 \%$.

Os resultados foram submetidos à análise de variância e as comparações entre as médias foram realizadas para os tratamentos das parcelas, das subparcelas e para os efeitos da interação entre os fatores, sendo comparadas pelo teste de Tukey, a 5\% de probabilidade, com o programa estatístico Sisvar 5.3 (Ferreira, 2000).

\section{RESULTADOS E DISCUSSÃO}

De acordo com a análise de variância, não houve efeito significativo da interação cultivar $\mathrm{x}$ sistemas de colheita para algumas características da fibra, como o índice de micronaire, a uniformidade de comprimento, a resistência, o conteúdo de impurezas, a área e a maturidade. Portanto, os resultados dessas características serão discutidos separadamente dos resultados entre os sistemas de colheita.

As características da fibra foram influenciadas pelo sistema de colheita, tendo a colheita manual apresentado o maior índice de micronaire, a maior uniformidade de fibras, maior resistência, a maior maturidade da fibra, o menor índice de fiabilidade e a menor área coberta por impurezas (Tabela 1). Observando-se os dados da Tabela 1, nota-se que os sistemas mecanizados de colheita modificaram as características da fibra do algodão, corroborando os resultados de Silva et al. (2010), ao relatarem que o

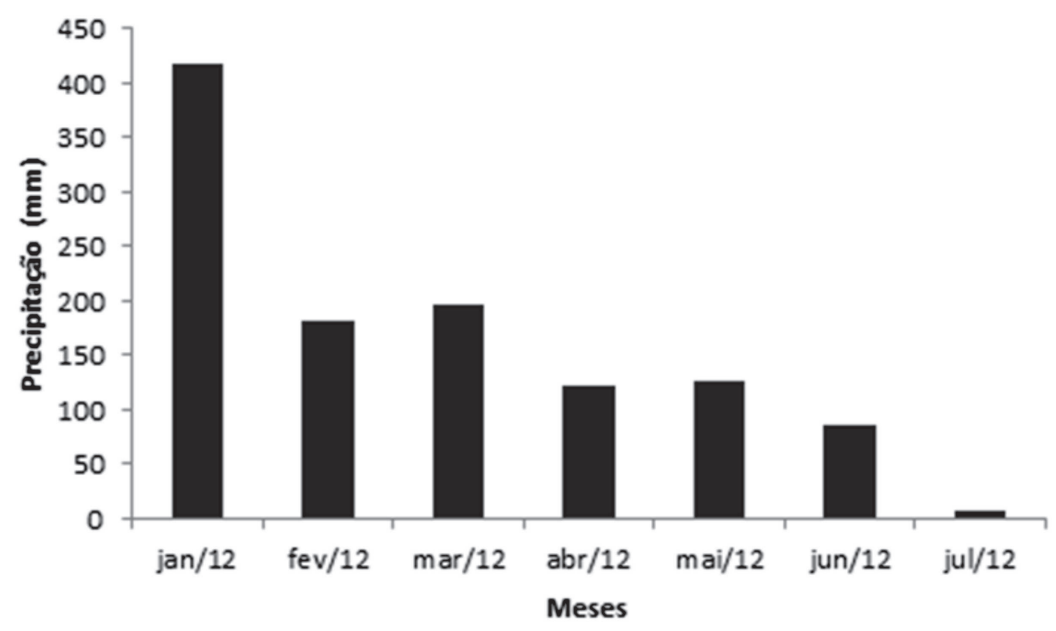

Figura 1: Precipitação pluviométrica (mm) acumulada mensal na área experimental, no período de janeiro a julho de 2012. 
modo de colheita condiciona a qualidade da fibra. A maioria dos traços fenotípicos em plantas é de natureza quantitativa e controlada não só pelo fator genético, mas também pelo ambiente e pela interação genótipo x ambiente (Mei et al., 2012).

O cultivar FMT 701 apresentou o maior índice de micronaire e o maior resultado para maturidade da fibra. As demais características não apresentaram diferenças significativas entre os cultivares. Esse resultado mostra que o cultivar FMT 701 apresentou maior maturidade e, ao mesmo tempo, maior finura das fibras.

Os maiores resultados de cht e área foram observados no sistema stripper $(55 ; 2,5 \%)$, diferindo daqueles do sistema picker $(37 ; 1,6 \%)$; o menor resultado observou-se no sistema de colheita manual $(8 ; 0,2 \%)$. Esses valores podem ser explicados pelo mecanismo de extração dos capulhos, pois, na colheita manual, retira-se seletivamente o algodão em caroço com o mínimo de impurezas, justificando-se o menor resultado obtido. Entretanto, o sistema de colheita stripper consiste no arranquio pelos pentes da plataforma, recolhendo os capulhos com brácteas e fragmentos lenhosos, resultando, portanto, no maior índice de impurezas.

De acordo com a norma ASTM (2010) D 1448-79 (American Society for Testing and Materials), os resultados de todos os tratamentos para índice de micronaire foram caracterizados como regulares ou médios (4,0 a 4,9), concordando com os de Fromme et al. (2014). Já Clement et al. (2013) observaram que o micronaire também encontrava-se entre 4,0 e 4,9, em sete dos oito genótipos avaliados na Austrália. Para o cv. FMT 701, os valores estão dentro das médias observadas por Echer et al. (2009). McAlister III \& Rogers (2005), quando avaliaram a influência dos sistemas de colheita sobre a qualidade da fibra, em Kingstree, South Carolina, observaram redução significativa do micronaire entre picker $(3,47)$ e stripper $(2,36)$, fato este não observado neste experimento, concordando, assim, com os resultados de Faircloth et al. (2004).

De acordo com a Instrução Normativa ${ }^{\circ} 63$, de 05 de dezembro de 2002, do MAPA (Brasil, 2002), a uniformidade de comprimento foi considerada Alta (83 a 85\%) e, segundo a norma ASTM (2012a) D1447, foi considerada elevada (83 a 85\%). Faulkner et al. (2011) avaliaram os sistemas mecanizados de colheita e observaram diferenças das Unf, de 80,4 (picker) para 79,4 (stripper). Neste experimento, não houve redução da Unf para os sistemas de colheita mecanizados.

Quanto à resistência à ruptura, as fibras, de acordo com Brasil (2002), foram consideradas como muito resistentes (31 $\mathrm{gf} \mathrm{tex}^{-1}$ ) e, pela norma ASTM (2012b) D1445 como muito elevadas (acima de 30), segundo Fonseca \& Santana (2002). Os sistemas de colheita mecanizados não influenciaram a resistência da fibra, corroborando resultados de Faulkner et al. (2011), que também não observaram diferenças de resistência entre os sistemas de colheita.

De acordo com Fonseca \& Santana (2002), o índice de maturidade percentual classificou como maduras ( $80 \mathrm{ou}$ mais) as fibras de todos os tratamentos.

Houve interação significativa entre os fatores para os parâmetros percentagem de fibra, comprimento, alongamento, grau de amarelecimento e grau de reflectância. Esses resultados estão apresentados em quadro de dupla entrada e serão discutidos conjuntamente ao longo do texto (Tabela 2).

Dentre as características buscadas no melhoramento do algodão está a percentagem de fibra, que é um dos componentes da produção de pluma. A maior percentagem de fibra foi encontrada nos sistemas de colheita manual e picker, com o cultivar IMACD 408.

Constatou-se na literatura que o parâmetro percentagem de fibra varia constantemente entre cultivares (Clement

Tabela 1: Resultados médios para micronaire (Mic), uniformidade do comprimento (Unf), resistência à ruptura (Str), conteúdo de impurezas (Cnt), percentual da área ocupada pelas impurezas (Area) e Maturidade percentual da fibra (Mat), em função dos cultivares e dos sistemas de colheita

\begin{tabular}{lcccccc}
\hline Tratamentos & Mic & Unf $(\%)$ & Str $\left(\mathbf{g f ~ t e x}^{-1}\right)$ & Cnt & Área $(\%)$ & Mat $(\%)$ \\
\hline Cultivar & & & & & \\
\hline FMT 701 & $4,5 \mathrm{a}$ & $84,1 \mathrm{a}$ & $32,2 \mathrm{a}$ & $30 \mathrm{a}$ & $1,3 \mathrm{a}$ & $86,3 \mathrm{a}$ \\
IMACD 408 & $4,2 \mathrm{~b}$ & $84,4 \mathrm{a}$ & $31,5 \mathrm{a}$ & $37 \mathrm{a}$ & $1,6 \mathrm{a}$ & $85,3 \mathrm{~b}$ \\
\hline Sistema de colheita & & & & & \\
\hline Manual & $4,9 \mathrm{a}$ & $85,0 \mathrm{a}$ & $33,0 \mathrm{a}$ & $8 \mathrm{c}$ & $0,2 \mathrm{c}$ & $87,5 \mathrm{a}$ \\
Picker & $4,0 \mathrm{~b}$ & $83,8 \mathrm{~b}$ & $31,4 \mathrm{~b}$ & $37 \mathrm{~b}$ & $1,6 \mathrm{~b}$ & $84,7 \mathrm{~b}$ \\
Stripper & $4,1 \mathrm{~b}$ & $83,9 \mathrm{~b}$ & $31,2 \mathrm{~b}$ & $55 \mathrm{a}$ & $2,5 \mathrm{a}$ & $85,1 \mathrm{~b}$ \\
\hline CV 1 $(\%)$ & 7,27 & 0,45 & 3,33 & 29,85 & 26,00 & 0,75 \\
\hline CV 2 $(\%)$ & 8,28 & 0,76 & 3,29 & 25,68 & 28,06 & 1,02 \\
\hline
\end{tabular}

Médias seguidas de mesma letra não diferem entre si pelo teste de Tukey ( $\geq \geq 0,05)$; CV 1: Coeficiente de variação para as médias das cultivares. CV 2: Coeficiente de variação para as médias dos sistemas de colheita. 
et al., 2013; Silva, 2014). Houve redução significativa do percentual de fibra entre os sistemas de colheita. Levando-se em conta que esse parâmetro é um dos componentes para produção de pluma, percebe-se que o sistema stripper diminui consideravelmente o rendimento de pluma e o do sistema picker não diferiu estatisticamente dos índices encontrados no sistema manual.

O comprimento da fibra é de extrema importância para a comercialização da pluma, pois quanto mais longa, melhor é a fibra, que, assim, proporciona fios mais fortes e finos. Os resultados de comprimento encontrados neste trabalho (Tabela 2) caracterizam a fibra como média, de acordo com Brasil (2002), pois seus maiores comprimentos variam de 30,2 a 30,4 mm. Os sistemas de colheita não influenciaram o comprimento de fibra do cv. FMT 701, mas, quanto ao cv. IMACD 408, nota-se discreto incremento do comprimento, do sistema de colheita manual $(28,4)$ aos sistemas picker (30,4 mm) e stripper (30,2 mm).

Na Tabela 3, observa-se que os resultados do sistema de colheita manual diferiram daqueles dos sistemas picker e stripper somente para o cultivar $701 \mathrm{e}$, nos sistemas de colheita manual e picker, o cultivar FMT 701 apresentou os menores valores de alongamento. Para o cv. FMT 701, os resultados de alongamento mostraram-se menores do que os encontrados por Echer et al. (2009), avaliando o mesmo cultivar.

Segundo a norma ASTM (2012b) D 1445, todos os valores de alongamento da fibra caíram na classe Frágil (5,0 a $5,9 \%$ ) e, segundo Brasil (2002), os resultados caíram na classe Baixo (5,0 a 5,8\%). O alongamento permite avaliar o comportamento elástico do material têxtil submetido a um esforço de tração, proporcionando uma ideia sobre a fiabilidade esperada (Fonseca \& Santana, 2002). As fibras de algodão são um modelo de desenvolvimento celular e alongamento, que ocorre em quatro estádios: iniciação, alongamento, síntese da segunda parede celular e maturação (Kim \& Triplett, 2001).

O menor índice de fibras curtas (Tabela 3) correspondeu ao cv. FMT 701 no sistema de colheita manual; os dos demais tratamentos não diferiram entre si, variando de 6,6 a 7,1. De acordo com Brasil (2002), os dados encontrados neste estudo são considerados baixos (de 6 a 9). Os resultados concordam com os de Faulkner et al. (2011) e de Faircloth et al. (2004) que não encontraram diferenças significativas entre os sistemas de colheita mecanizados. Porém, McAlister III \& Rogers (2005) observaram incremento significativo entre os sistemas de colheita picker $(9,5) \mathrm{e}$ stripper $(16,7)$ para o SFI.

Tabela 2: Resultados médios de percentagem de fibra (\%) e comprimento médio da metade das fibras mais longas (UHM), em função dos cultivares e dos sistemas de colheita

\begin{tabular}{|c|c|c|c|c|}
\hline \multirow{3}{*}{ Sistemas de colheita } & \multicolumn{2}{|c|}{ Percentagem de Fibra } & \multicolumn{2}{|c|}{ UHM (mm) } \\
\hline & \multicolumn{4}{|c|}{ Cultivar } \\
\hline & FMT 701 & IMACD 408 & FMT 701 & IMACD 408 \\
\hline Manual & $41,47 \mathrm{aB}$ & $42,84 \mathrm{aA}$ & $30,2 \mathrm{aA}$ & $28,4 \mathrm{bB}$ \\
\hline Picker & $40,54 \mathrm{aB}$ & $42,67 \mathrm{aA}$ & $29,7 \mathrm{aB}$ & $30,4 \mathrm{aA}$ \\
\hline Stripper & $32,87 \mathrm{bA}$ & $32,11 \mathrm{bA}$ & $29,8 \mathrm{aA}$ & $30,2 \mathrm{aA}$ \\
\hline$\overline{\mathrm{CV}} 1(\%)$ & 2,01 & & 1,75 & \\
\hline $\mathrm{CV} 2(\%)$ & 2,48 & & 1,14 & \\
\hline
\end{tabular}

Tabela 3: Resultados médios para alongamento à ruptura (Elong) e índice de fibras curtas (SFI), em função dos cultivares e dos sistemas de colheita

\begin{tabular}{lcccc}
\hline \multirow{2}{*}{ Sistemas de colheita } & \multicolumn{3}{c}{ Elong (\%) } & \multicolumn{3}{c}{ CFI (\%) } \\
\cline { 2 - 5 } & FMT 701 & IMACD 408 & FMT 701 & IMACD 408 \\
\cline { 2 - 5 } & $4,90 \mathrm{bB}$ & $5,60 \mathrm{aA}$ & $5,30 \mathrm{bB}$ & $6,70 \mathrm{aA}$ \\
Manual & $5,38 \mathrm{aB}$ & $5,80 \mathrm{aA}$ & $7,12 \mathrm{aA}$ & $6,64 \mathrm{aA}$ \\
Sicker & $5,52 \mathrm{aA}$ & $5,60 \mathrm{aA}$ & $6,72 \mathrm{aA}$ & $6,60 \mathrm{aA}$ \\
\hline CV 1 (\%) & 3,92 & & 5,17 & \\
\hline CV 2 (\%) & 4,34 & & 6,02 & \\
\hline
\end{tabular}

Médias seguidas de mesma letra maiúscula na linha não diferem entre si pelo teste de Tukey ( $\geq 0$,05); Médias seguidas de mesma letra minúscula na coluna não diferem entre si pelo teste de Tukey ( $\mathrm{p} \geq 0,05)$; CV 1: Coeficiente de variação para as médias dos cultivares. CV 2: Coeficiente de variação para as médias dos sistemas de colheita. 
A busca em geral das indústrias têxteis é por plumas com maiores percentuais de reflectância e menores índices de amarelecimento. Neste experimento, observou-se que o grau de amarelecimento (Tabela 4) não variou entre os sistemas de colheita picker e stripper, para o cv. FMT 701. Houve, porém, redução significativa do amarelecimento na colheita stripper, em comparação com o amarelecimento observado na picker e na manual, para o cv. IMACD 408. Os índices de amarelecimento (+b) encontrados estão abaixo dos observados na literatura, sendo considerados adequados, uma vez que, quanto menor o grau de amarelecimento, melhor será sua classificação quanto à cor.

Os maiores resultados de reflectância foram apresentados pelo cv. FMT 701 e, dentre os sistemas de colheita, observa-se uma redução significativa, do sistema manual (85\%) para os sistemas de colheita picker $(75,9 \%)$ e stripper (74,02\%). Com esse resultado, percebe-se como a ação dos fusos rotativos (sistema picker), pente e rosca sem fim (sistema stripper) ocasionam redução na reflectância da fibra. O cv. IMACD 408 também apresentou redução significativa do grau de reflectância, do sistema de colheita manual para os demais. Entretanto, os sistemas mecanizados (picker e stripper) não diferiram entre si. Os dados encontrados situam-se acima dos relatados por Echer $e t$ al. (2009) para os cultivares analisados neste experimento.

A combinação dos índices de reflectância e de amarelecimento estabelece o grau de cor ou color grade (CG) da fibra do algodão (Tabela 5), representado por um código de três dígitos. O primeiro dígito é relativo ao tipo visual do algodão (para o que o tipo 1 é o melhor e o 8 já é considerado fora do padrão), o segundo dígito refere-se à cor (1-branco, 2-ligeiramente creme, 3-creme, 4-avermelhado e 5-amarelado) e o terceiro dígito representa um dos quadrantes localizados no diagrama de cores desenvolvido por Nickerson \& Hunter (Cotton Colorimeter baseado no Universal Standards for Grade of American Upland Cotton) (Brasil, 2002).

O índice de folhas (leaf) é um conceito utilizado pelo USDA (1994) (Departamento Norte Americano de Agricultura) e corresponde à incidência de impurezas (matéria não fibrosa) da amostra de algodão, quando comparada com os padrões físicos universais (Fonseca \& Santana, 2002). Observa-se, na Tabela 5, que o sistema de colheita manual originou os menores índices de folha. Entre os sistemas mecanizados este parâmetro variou de 4 a 6 , índices considerados aceitáveis na comercialização, segundo Costa et al. (2006).

Observa-se que no experimento obtiveram-se fibras de quatro tipos. O melhor tipo foi encontrado no sistema de colheita manual, por causa das características dessa modalidade de colheita, uma vez que se recolheram apenas os capulhos do algodão com o mínimo de impurezas. Para o cv. FMT 701, a fibra foi classificada como 11-2 (algodão de tipo visual 1 e cor branca). Para o cv. IMACD 408, a classificação da fibra foi tipo 31-2 (algodão tipo visual 3 e cor branca).

Tabela 4: Resultados médios do grau de amarelecimento (+b) e grau de reflectância (Rd), em função dos cultivares e dos sistemas de colheita

\begin{tabular}{lcccc}
\hline \multirow{2}{*}{ Sistemas de colheita } & \multicolumn{3}{c}{ +b } & \multicolumn{2}{c}{ Rd (\%) } \\
\cline { 2 - 5 } & \multicolumn{4}{c}{ Cultivar } \\
\cline { 2 - 5 } & FMT 701 & IMACD 408 & FMT 701 & IMACD 408 \\
\hline Manual & $6,9 \mathrm{aA}$ & $5,9 \mathrm{aB}$ & $85,00 \mathrm{aA}$ & $81,80 \mathrm{aB}$ \\
Picker & $5,8 \mathrm{bA}$ & $6,1 \mathrm{aA}$ & $75,94 \mathrm{bA}$ & $73,66 \mathrm{bB}$ \\
Stripper & $5,4 \mathrm{bA}$ & $5,2 \mathrm{bA}$ & $74,02 \mathrm{cA}$ & $73,90 \mathrm{bA}$ \\
\hline CV 1 $(\%)$ & 5,75 & & 1,72 & \\
\hline CV 2 $(\%)$ & 7,52 & & 1,31 & \\
\hline
\end{tabular}

Médias seguidas de mesma letra maiúscula na linha não diferem entre si pelo teste de Tukey ( $\geq \geq 0,05)$; Médias seguidas de mesma letra minúscula na coluna não diferem entre si pelo teste de Tukey ( $\mathrm{p} \geq 0,05)$; CV 1: Coeficiente de variação para as médias dos cultivares. CV 2: Coeficiente de variação para as médias dos sistemas de colheita.

Tabela 5: Resultados médios para grau de folha (LG) e grau da cor (CG) em função dos padrões físicos universais para os diferentes cultivares e sistemas de colheita

\begin{tabular}{lcccc}
\hline \multirow{2}{*}{ Sistemas de colheita } & \multicolumn{3}{c}{ LG } & \multicolumn{2}{c}{ CG } \\
\cline { 2 - 5 } & FMT 701 & IMACD 408 & FMT 701 & IMACD 408 \\
\cline { 2 - 5 } & 1 & 3 & $11-2$ & $31-2$ \\
Manual & 4 & 5 & $41-2$ & $41-2$ \\
Picker & 6 & 6 & $51-2$ & $51-2$ \\
Stripper & & &
\end{tabular}

Rev. Ceres, Viçosa, v. 63, n.5, p. 631-638, set/out, 2016 
Os tipos de fibra obtidas nos sistemas de colheita picker e stripper não diferiram entre os cultivares. O sistema de colheita picker resultou em 41-2 (algodão de tipo visual 4 e cor branca) e, o sistema stripper, em algodão de tipo 512 (algodão de tipo visual 5 e cor branca). Esses tipos quando comparados com 11-2 e 31-2 (sistema manual) são considerados de pior qualidade.

Boldrin (2011), em pesquisa de campo com os cotonicultores da Associação Mato-grossense dos Produtores de Algodão (AMPA), observou que 85\% dos cotonicultores produzem algodão do tipo $31-4$; $60 \%$ produzem do tipo 41-4 e apenas 5\% produzem do tipo 51-5. Martin (2006), em estudos com comercialização de algodão em pluma, explanou que a fibra de colheita stripper é menos procurada, além de ser comercializada com deságios, por apresentar tipo inferior. As bolsas de valores aplicam ágios e deságios de acordo com a classificação do algodão comercializado. Esses critérios utilizados na comercialização mostram o quanto a qualidade do produto é levada em consideração pelos agentes, pois, quanto melhores os padrões atingidos pelos produtores, maiores serão os ágios recebidos. Portanto, a busca pela melhoria de qualidade da fibra ocasionada pela colheita mecanizada é necessária, pois assim será possível ao produtor obter melhores preços no mercado.

\section{CONCLUSÕES}

Os sistemas mecanizados de colheita influenciaram todas as variáveis das características da fibra do algodão, demonstrando que as impurezas influenciam diretamente a qualidade do algodão.

As fibras do algodão colhido com sistema manual, em seguida, picker apresentam características e tipo de melhor qualidade que os das fibras colhidas com stripper.

\section{REFERÊNCIAS}

ASTM - American Society for Testing and Materials (2010) ASTM C1448 - Standard Specification for Non-Asbestos Fiber-Cement Conduit. Disponível em: <http://www.astm.org/Standards/ C1448.htm>. Acessado em: 02 de março de 2013.

ASTM - American Society for Testing and Materials (2012a) ASTM D1447-07 - Standard Test Method for Length and Length Uniformity of Cotton Fibers by Photoelectric Measurement. Disponível em: <http://www.astm.org/Standards/D1447.htm>. Acessado em: 02 de março de 2013.

ASTM - American Society for Testing and Materials (2012b) ASTM D1445 - Standard Test Method for Breaking Strength and Elongation of Cotton Fibers (Flat Bundle Method). Disponível em: <http://www.astm.org/Standards/D1445.htm>. Acessado em: 02 de março de 2013.

ASTM - American Society for Testing and Materials (1995) ASTM D4605-86 - Test Method for Measurement of Cotton Fibers by High Volume Instruments (HVI): Special Instruments Laboratory System. Disponível em: <http://www.astm.org/DATABASE. CART/WITHDRAWN/D4605.htm>. Acessado em: 02 de março de 2013
Baxevanos D, Tsialtas IT \& Goulas C (2013) Repeatability and stability analysis for fiber traits in upland cotton (Gossypium hirsutum L.). Crop Science, 7:1423-1429.

Belot JL \& Vilela PMC (2006) Colheita de algodão. Cuiabá, FACUAL. 390p.

Boldrin DL (2011) Diretrizes competitivas para o setor do algodão do estado de Mato Grosso: Desafios das próximas décadas. Dissertação de Mestrado. Universidade Federal de Mato Grosso, Cuiabá. 69p.

Brasil (2002) Instrução Normativa $n^{\circ} 63$, de 5 de dezembro de 2002. Aprova o Regulamento técnico de Identidade e de Qualidade para a Classificação do Algodão em Pluma. DOU, 6/12/ 2012, Seção 1, p.6-8.

Chanselme J \& Ribas PV (2010) Beneficiamento do algodão adensado e qualidade da fibra. Cuiabá, Defanti. 390p.

Clement JD, Constable GA \& Conaty WC (2013) $\mathrm{CO}_{2}$ exchange rate in cotton does not explain negative associations between lint yield and fiber quality. The Journal of Cotton Science, $17: 270-278$.

CONAB - Companhia Nacional de Abastecimento (2014) Acompanhamento da safra brasileira de grãos: Décimo Segundo Levantamento. Safra 2013/14. Disponível em: <http:// www.conab.gov.br/OlalaCMS/uploads/arquivos/ 14_09_10_14_35_09_boletim_graos_setembro_2014.pdf >. Acessado em: 10 de dezembro de 2014.

Costa JN, Santana JCF, Wanderley MJR, Andrade JEO \& Sobrinho RE (2006) Padrões Universais para Classificação do Algodão. Campina Grande, Embrapa Algodão. 23p. (Documentos, 151).

Echer FR, Foloni JSS \& Creste JE (2009) Fontes de potássio na adubação de cobertura do algodoeiro I - Produtividade, qualidade de fibras e análise econômica. Semina: Ciências Agrárias, 30:1135-1144.

Embrapa - Empresa Brasileira de Pesquisa Agropecuária (2003) Cultura do algodão no cerrado: Colheita. Disponível em: <http:/ /sistemasdeproducao.cnptia.embrapa.br/FontesHTML/Algodao/ AlgodaoCerrado/colheita.htm>. Acesado em: 10 de dezembro de 2015 .

Embrapa - Empresa Brasileira de Pesquisa Agropecuária (2006) Sistema Brasileiro de Classificação de Solos. $2^{a}$ ed. Brasília, Embrapa. 306p.

Faircloth JC, Hutchinson R, Barnett J, Paxson K, Coco A \& Price III P (2004) An evaluation of alternative cotton harvesting methods in Northeast Louisiana - A Compararison of the Brush Stripper and Spindle Harvester. Journal of Cotton Science, 8:5561 .

Faulkner WB, Wanjura JD, Hequet EF, Boman RK, Shaw BW \& Parnell Jr CB (2011) Evaluation of modern cotton harvest systems on irrigated cotton: fiber quality. Applied Engineering in Agriculture, 27:507-513.

Ferreira DF (2000) Manual do sistema Sisvar para análises estatísticas. Lavras, UFLA. 66p.

Fonseca RG \& Santana JCF (2002) Resultados de Ensaio HVI e Suas Interpretações (ASTM D-4605). Campina Grande, Embrapa Algodão. 13p. (Circular Técnica, 66).

Fromme DD, Cothren JT, Lemon RG \& Bynum J (2014) Effect of na upper temperature threshold on heat unit calculations, defolioation timing, lint yield, and fiber quality in cotton. The Journal of Cotton Science, 18:108-121.

Fundação Mato Grosso (2012) Cultivares convencionais: 701. Disponível em: <http://www.fundacaomt.com.br/algodao/ ?cult=fmt701>. Acessado em: 03 de janeiro de 2012. 
IMEA - Instituto Mato-grossense de Economia Agropecuária (2014) Boletim Semanal do Algodão. Disponível em: <http:// imea.com.br/upload/publicacoes/arquivos/R104_Estimativa_ de_Safra_Algodao_13-14_out.pdf $>$. Acessado em: 01 de março de 2015.

Iype C \& Wan TR (1998) Nep structure and analysis using image processing methods. Textile Research Journal, 68:889-899.

Kim HJ \& Triplett BA (2001) Cotton fiber growth in planta and in vitro. Models for plant cell elongation and cell wall biogenesis Plant Physiology 127:1361-1366.

Krieg DR \& Hequet EF (2005) Fiber quality variation within a cotton plant as affected by genetics and environment. Proceeding of Beltwide Cotton Conferences, 4:2390-2385.

Martin J (2006) Avanços das pesquisas sobre algodão ultraadensado. Cuiabá, FACUAL. 390p.

Mcalister III DD \& Rogers CD (2005) The effect of harvesting procedures on fiber and yarn quality of ultra-narrow-row cotton. Journal of Cotton Science, 9:15-23.

Mei Y, Zhou J, Xu H \& Zhu S (2012) Development of sea island cotton (Gossypium barbadense L.) core collection using genotypic values. Crop Science, 6:673-680.

Pujer SK, Siwach SS, Sangwan RS, Sangwan O \& Deshmukh J (2014) Correlation and path coefficient analysis for yield and fibre quality traits in upland cotton (Gossypium hirsutum L). Journal Cotton Research Development, 28:214-216.
Pupim-Junior O, Belot JL, Vilela PCA, Zambiasi TC, Martin J, Ribeiro GA \& Ferreira DS (2005) CD 408 - Variedade de algodão de alto potencial e estabilidade produtividade para as regiões do sul do Brasil. Disponível em: <http:// www.cnpa.embrapa.br/produtos/algodao/publicacoes/ trabalhos_cba5/245.pdf> Acessado em: 17 de janeiro de 2013.

Rosolem CA, Echer FR, Lisboa IP \& Barbosa TL (2012) Acúmulo de nitrogênio, fósforo e potássio pelo algodoeiro sob irrigação cultivado em sistema convencional e adensado. Revista Brasileira de Ciência do Solo, 36:457-466.

Saha S, Jenkins JN, Wu J, McCarty JC \& Stelly DM (2008) Genetic analysis of agronomic and fiber traits using four interspecific chromos substitution lines in cotton. Plant Breeding, 127:612618 .

Sestren JA \& Lima JJ (2015) Características e classificação da fibra de algodão. In: Freire EC (Ed.) Algodão no cerrado do Brasil. Associação Brasileira dos Produtores de Algodão ABRAPA. $3^{\text {a }}$ ed. Brasília, Gráfica e editora Positiva. p.653-750.

Silva DJ (2014) Predição não destrutiva de propriedades físicas e química em fibras de algodão naturalmente colorido. Dissertação de Mestrado. Universidade Estadual da Paraíba, Campina Grande. 57p.

Silva ORRF da, Sofiatti V \& Belot J-L (2010) Colheita do algodão adensado. In: Belot JL \& Vilela PA (Eds.) O Sistema de Cultivo do Algodoeiro Adensado em Mato Grosso. Cuiabá, Editora Defanti. p.293-310.

USDA (1994) Cotton Ginners Handbook. Washington, USDA. 348 p. 